\title{
ARTIGOS
}

\section{GÊNERO E RAÇA: \\ INTERSECÇÕES, MOVIMENTOS SOCIAIS E O ENFRENTAMENTO À VIOLÊNCIA}

\section{Karoline Soares Chaves ${ }^{1}$}

1. Resum̄o: O objetivo deste artigo é estabelecer uma relação entre o conceito de gênero enquanto categoria de análise com o corpus teórico do que delimitamos como feminismo negro. Para tal é necessário expor os limites e possibilidades do gênero como

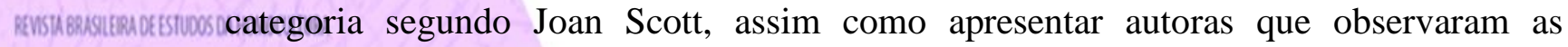
necessidades do feminismo interseccionar-se com o debate sobre as questões da raça. É no bojo deste debate que verificamos as ações de enfrentamento à violência promovidas pelos movimentos sociais organizados, a saber e em especial a Marcha das Mulheres Negras. O fluxo de nossa análise se guia por três momentos distintos: compreender de modo genealógico o gênero como categoria de análise; os debates sobre identidade e negritude a partir de leituras feministas e o relato crítico do movimento de formação da Marcha de Mulheres Negras.

Palavras-chave: Gênero; Raça; Marcha das mulheres negras.

\section{Gênero como categoria de análise}

Joan Scott em seu artigo, Gênero uma categoria útil de análise histórica, publicado no Brasil em 1995, põe em evidência que o uso do termo Gênero tem uma conotação mais objetiva e neutra que a categoria 'mulheres'. Sendo assim, este se ajustaria de forma mais científica às ciências sociais dissociando-se da política do feminismo. O gênero incluiria as mulheres sem mencionar, de forma estratégica, o que parecia ser uma forte ameaça nos anos 1980, quando se buscava uma legitimidade acadêmica para os estudos feministas.

\footnotetext{
${ }^{1}$ Advogada e Mestre pelo Programa de Pós-Graduação em Desenvolvimento Regional pela Universidade Federal do Tocantins (UFT).
} 
Sendo assim, estudar o termo gênero é também uma forma de estudar mulheres. Cabe ainda destacar que a pensadora americana é enfática em suas matrizes teóricas advinda do movimento na Nova História ${ }^{2}$ e do Pós-estruturalismo ${ }^{3}$.

Desta forma, o termo gênero constituiu-se como um instrumento analítico para designar as relações sociais entre os sexos, definindo-se como uma "categoria social imposta sobre um corpo sexuado" (SCOTT, 1995, p.80).

No entanto, este sistema de relações pode incluir o sexo, mas não é diretamente determinado por este e nem determina a sexualidade do indivíduo, limitando-se a D. contribuir com a afirmação de que as relações entre os sexos são sociais, silenciando a respeito dessas razões. Para tanto, a autora traz uma observação sobre a construção desta categoria como ferramenta de análise, a saber:


hierárquica da relação entre masculino e feminino, em seus contextos específicos, e uma tentativa para reverter ou deslocar suas operações. Os/as historiadores/as feministas estão agora bem posicionados/as para teorizar suas práticas e para desenvolver o "gênero" como uma categoria analítica (SCOTT, 1995, p.84).

A categoria gênero esteve ausente das principais abordagens de teorias sociais tecidas desde o século XVIII. A preocupação teórica com gênero só emergiu no final do século XX, quando algumas dessas teorias construíram sua lógica partindo das analogias com a 'questão feminina' - ponderadas de modo globalmente conhecido por Betty Friedan - com a dicotomia feminino/masculino, ou até mesmo com uma formulação ligada a identidade sexual, porém, como uma forma de relatar e analisar sistemas de relações sociais, "tal conceito ainda não havia aparecido" (SCOTT, 1995, p.85).

A criação desta categoria fez parte de uma estratégia para reivindicar um terreno de definição que explicasse as persistentes desigualdades entre mulheres e homens. $\mathrm{O}$ que fez com que se criasse um espaço para que as teóricas feministas se posicionassem criticamente na ciência desenvolvida pelas humanidades, pelo empirismo, pelos pósestruturalistas, encontrando aliados acadêmicos e políticos.

\footnotetext{
${ }^{2}$ É salutar destacarmos que a historiadora em questão está posicionada no que os especialistas chamam de terceiro movimento da École dês annales - escola dos anais - corrente que impulsionou novos horizontes no campo da historiografia. Para uma compreensão datada e elaborada da corrente é possível observar a leitura da obra de Peter Burke, Escola dos annales - 1929-1989, publicado pela editora da UNESP em 2003.

${ }^{3}$ Ao filiarmos nossa pesquisadora ao Pós-estruturalismo, identificamos a influência de Jaques Derrida em suas pesquisas e teorias. Sendo assim, é importante reiterarmos a figura do Pós-estruturalismo como corrente, majoritariamente, francesa que influenciou diversas áreas das ciências humanas.
} 
Uma parte crucial da organização da sociedade em igual e desigual diz respeito a estruturas hierarquizadas que dependem de "compreensões generalizadas das relações naturais em mulheres e homens" (SCOTT, 1995, p.91).

Ao longo da exposição de Joan Scott podemos identificar a necessidade e a legitimidade das investigações sociais considerarem o gênero como instrumento capaz de, não somente dizer da realidade social, mas também emitir em padrões, ainda limitados, condições inéditas de observação da realidade social sobre o cunho sociológico e epistêmico das e para as mulheres.

No entanto, é preciso pensar na diversidade destas mulheres, para que sejam D criadas alianças entre mulheres diferentes, e, em se tratando de identidades diferentes, este estudo tem a pretensão de se debruçar mais especificadamente sobre as mulheres Rastibnglemotestuosos negras como veremos a seguir.

\section{A mulher negra}

Antes de começar a descrever a categoria mulher negra, primeiramente é importante contextualizar a questão racial na sociedade capitalista, bem como seus impasses e dilemas, marcada por um sistema desigual que não reconhece a população negra como sujeito de direito. Dessa maneira, para compreender a subalternidade da população negra, de uma forma ampla Joaze Bernadido Costa (2015), descreve-a a partir da 'história-mítica' de Gilberto Freyre (1999),

Gilberto Freyre, em 1933, não só reconstrói como cria uma interpretação do Brasil a partir da casa grande e senzala, o que nos permite visualizar uma "história-mítica" das trabalhadoras domésticas e da divisão sexual e racial do trabalho. Para Freyre, a casa-grande e a senzala se constituíram na unidade do entendimento do Brasil. Freyre, um autor fortemente comprometido com um projeto de construção da nação, argumenta que senhores e escravos, brancos e negros estavam hierarquicamente integrados, complementando-se. Assim, sua historiografia, fortemente baseada na história íntima da família brasileira, defende que inauguramos um sistema social democrático tanto do ponto de vista econômico quanto racial, aberto à mobilidade social de negros e pobres (BERNARDINO-COSTA, 2015, p. 21).

$\mathrm{O}$ autor acrescenta ainda que,

Todavia a ascensão social se daria preferencialmente pela miscigenação, cujo produto seria o chamado mulato. A miscigenação, por sua vez, ocorreria principalmente por meio da escrava de casa, a mucama. Nesse sistema social, a escrava de casa seria hierarquicamente superior às escravas da senzala e, consequentemente desfrutaria de alguns privilégios. Do relacionamento íntimo com entre família patriarcal e escrava redundaria o mulato, o filho bastardo do senhor de engenho e da escrava da casa, que, ao invés de se revoltar contra o seu pai, por não ser filho legítimo, imitava-o, por meio da assimilação de valores europeus (BERNARDINO-COSTA, 2015, p. 22). 
Percebe-se que a construção do negro, no Brasil, se dá diretamente ligada a exploração pelo branco, em um primeiro momento e, até os dias atuais, a cidadania da população negra ainda não é plena.

O Brasil buscou sistematicamente incentivar a imigração europeia por questões econômicas e também para que houvesse o embranquecimento da população. A herança africana no Brasil é assumida apenas quando interessa, para mostrar ao mundo que somos um país multirracial. No Brasil, o preconceito é de cor e não de origem, como D 1 nos EUA. Aqui os refugiados africanos são mais suscetíveis ao preconceito e ao nit. racismo, já que a pele de cor é associada às periferias e as pessoas que não tem acesso à saúde e a educação. Já os refugiados mulçumanos, sírios e árabes são considerados

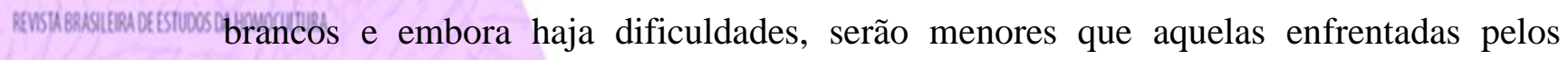
refugiados do Haiti ou de África (RUFATTO, 2016).

Para Abdias Nascimento,

(...) erigiu-se no Brasil o conceito de democracia racial; segundo esta, pretos e brancos convivem harmoniosamente, desfrutando iguais oportunidades de existência. (...) A existência dessa pretendida igualdade racial constitui o 'maior motivo de orgulho nacional' (...). No entanto, devemos compreender democracia racial como significando a metáfora perfeita para designar o racismo estilo brasileiro: não tão óbvio como o racismo dos Estados Unidos e nem legalizado qual o apartheid da África do Sul, mas eficazmente institucionalizado nos níveis oficiais de governo assim como difuso no tecido social, psicológico, econômico, político e cultural da sociedade do país (NASCIMENTO, 1978, p.41; 92).

Depreendemos que democracia racial significa um sistema racial desprovido de qualquer barreira legal ou institucional para a igualdade racial, até mesmo um sistema racial desprovido de qualquer manifestação de preconceito ou discriminação (DOMINGUES, 2005).

A lei Áurea, em 1888, aboliu a escravidão, o principal dispositivo institucional de opressão dos negros no Brasil. Em 1889, a proclamação da República universalizou, em tese, o direito à cidadania. Do ponto de vista do discurso legal, cidadãos negros passariam a desfrutar de uma igualdade de direitos e oportunidades em relação aos brancos em todas as áreas da vida pública: educação, emprego, moradia, terra, saúde, lazer, etc. No entanto, não podemos esquecer que, segundo o artigo 70, título IV, da Constituição de 1891, não tinham direitos políticos, ou seja, não podiam votar e ser votados, entre outros, os analfabetos, condição na qual se encontrava a maioria da população negra, em São Paulo, no alvorecer da República. Assim, a inexistência da igualdade política anulava, na prática, muito dos supostos avanços da teoria (DOMINGUES, 2005, p.116-117). 
De forma que, quando racionalizamos teoricamente o que foi chamado de 'democracia racial', observamos que Gilberto Freyre, na obra Casa-Grande \& Senzala, de 1933, catalisou os fundamentos de um mito construído historicamente pela classe dominante, mas que foi aceito, no geral, por camadas das demais classes sociais e, em particular, por um setor da população negra. Esta obra teve a capacidade de canalizar a representação popularizada das relações entre negros e brancos do país e transformá-la na ideologia racial oficial. E, embora Freyre não tenha fundado o mito da democracia racial, ele o consolidou e elevou ao plano considerado científico, um imaginário das D. relações raciais, fortemente arraigado no pensamento nacional (DOMINGUES, 2005). No campo da cidadania, o Brasil para Milton Santos (1997) é um país que
nunca pode construir uma ideia de cidadania, que nunca teve uma cidadania, pois este

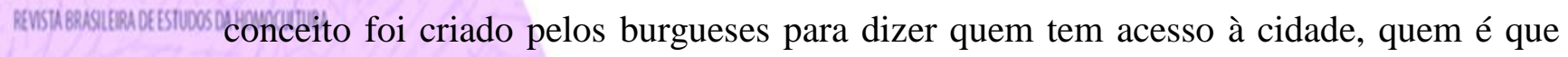
detém o capital. Quem tem direito a cidade é quem tem dinheiro, moeda de troca, de comercialização. Então, nunca houve cidadania, sobretudo no Brasil e na América Latina (nos países terceiro mundistas).

Nesses países é que há a necessidade de conceituar cidadania, pois no Brasil há a necessidade de se dizer que é preciso ter cidadãos. Se formos nos ater aos países desenvolvidos, esta discussão é incipiente, pois, em tese, o índice de desenvolvimento humano nesses países dá acesso à cidade a qualquer pessoa. Ainda que a distribuição de renda seja diferente, ineficiente, a cidade é dada sobremaneira para todos. Países com diferentes perspectivas sobre sociedade vão dizer quem tem ou não direito à cidade. Mas, então, já não há cidadania, e sim, a cidadania mutilada (SANTOS, 1997).

Santos (1997) explica que há os que não querem ser cidadãos, que são as classes médias, e há os que não podem ser cidadãos, que são todos os demais, a começar pelos negros que não são cidadãos. E, ainda declara que, o faz por si mesmo. "Não importa a festa que me façam aqui ou ali, o cotidiano me indica que não sou cidadão neste país" (SANTOS, 1997, p. 134).

Sendo assim, mesmo quando a 130 anos da suposta libertação de escravos, fica mais nítido compreender que faltam ainda muitos passos, para que a população negra tenha o mesmo acesso à saúde, à educação de qualidade, às mesmas condições de trabalho.

No tocante a reflexão sobre a mulher negra, a abordagem deste artigo é realizada a partir das análises de Sueli Carneiro (2003; 2015), Lélia Gonzalez (1984, 1988a) e Kimberlé Crenshaw (2002). 
O racismo no Brasil ainda produz grandes violações de direitos, por parte do próprio Estado, exclusão e marginalização de cidadãs e cidadãos. A população negra é a maior no sistema penitenciário, a juventude negra é a mais exterminada pelo Estado e sâo as mulheres negras que mais morrem em todo o Brasil, em especial na região norte. Posto isto, não se pode negar a existência desta realidade, se assim o fosse estaríamos negligenciando a história de uma população que luta cotidianamente para sobreviver. Nas palavras de Sueli Carneiro,

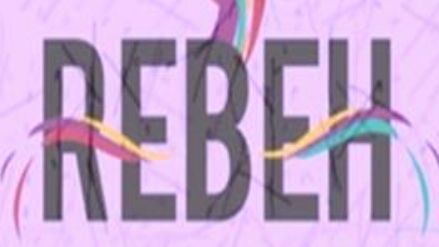

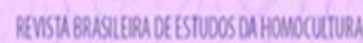

No Brasil e na América Latina, a violação colonial perpetrada pelos senhores brancos contra as mulheres negras e indígenas e a miscigenação daí resultante está na origem de todas as construções de nossa identidade nacional, estruturando o decantado mito da democracia racial latinoamericana, que no Brasil chegou até as últimas consequências. Essa violência sexual colonial é, também, o 'cimento' de todas as hierarquias de gênero e raça presentes em nossas sociedades [...] (CARNEIRO, 2015, p.01).

Neste sentido é importante contextualizar o debate da autora em questão à relação com o Movimento $\mathrm{Negro}^{4}$ Unificado (MNU), como movimento social que tem colaborado na luta contra tais hierarquias, pensando a construção das mesmas desde o processo de colonização do Brasil, quando a população negra foi escravizada e traficada para as Américas.

[...] o MNU aparece nesse bojo, trazendo propostas às minhas indagações. Criado em 07 de julho de [19]78 (há 36 anos), em ato público com cerca de duas mil pessoas, em frente ao Teatro Municipal de São Paulo, se propunha a ser uma organização de lutas e denúncias em todos os campos onde haja opressão e perseguição do negro, ou seja, um órgão de forte representatividade da população negra em sua luta pela liberdade. O MNU ainda nesse ano, em sua segunda Assembleia Nacional, em Salvador, proclamava o 20 de novembro como "Dia Nacional da Consciência Negra" (MACHADO, 2014, p.02).

No entanto, as discussões de gênero e feminismo que as teóricas e, até mesmo o Movimento de Mulheres propunham, não contemplavam as mulheres negras, e nem mesmo, o Movimento Negro, fazia o recorte de gênero em suas análises e lutas. Assim, eram/são as mulheres negras que sofrem de forma mais incisiva e que no seu cotidiano lidam com o racismo, com a subalternidade e com a discriminação (MOREIRA, 2017).

Neste sentido, Sueli Carneiro (2011) aponta que as mulheres negras tiveram uma experiência histórica diferenciada das mulheres brancas, "o discurso clássico sobre a opressão da mulher não tem reconhecido, assim como não tem dado conta da

\footnotetext{
${ }^{4}$ Este traz o conceito de Movimento Negro, com o aporte em Helena Vitória dos Santos Machado (2014), que entende que a expressão Movimento Negro abarca as manifestações de protesto ou afirmação negra, ocorridas desde os porões dos navios negreiros. O Movimento Negro Unificado, possivelmente, foi o primeiro a marcar seu nome com a referida expressão.
} 
diferença qualitativa que o efeito da opressão sofrida teve e ainda tem na identidade feminina das mulheres negras" (CARNEIRO, 2011, p. 01).

A opressão da mulher sempre veio, na perspectiva de pensadoras como Betty Friedan (1971) e Nancy Fraser (2002), atrelada a questão da dominação patriarcal. Tais teóricas carregam no bojo de suas análises a dependência econômica como o nó, muitas vezes impossível de se desatar, e revelam, que a liberdade econômica e a liberdade sexual fazem parte de uma possível escala de emancipação. Porém, Sueli Carneiro (2011) nos diz que opressão, trabalho, corporalidade não podem ser pensados do mesmo D. modo quando se requer a marca identitária da negritude para as mulheres. A autora diz nLbin

Quando falamos do mito da fragilidade feminina, que justificou historicamente a proteção paternalista dos homens sobre as mulheres, de que mulheres estamos falando? Nós, mulheres negras, fazemos parte de um contingente de mulheres, provavelmente majoritário, que nunca reconheceram em si mesmas esse mito, porque nunca fomos tratadas como frágeis. Fazemos parte de um contingente de mulheres que trabalharam durante séculos como escravas nas lavouras ou nas ruas, como vendedoras, quituteiras, prostitutas... Mulheres que não entenderam nada quando as feministas disseram que as mulheres deveriam ganhar as ruas e trabalhar! Fazemos parte de um contingente de mulheres com identidade de objeto. Ontem, a serviço de frágeis sinhazinhas e de senhores de engenho tarados. Hoje, empregadas domésticas de mulheres liberadas e dondocas, ou de mulatas tipo exportação (CARNEIRO, 2011, p. 01-02).

Foi na segunda onda do feminismo, compreendida a partir do final da década de 1960 e começo da década de 1970, que se originou nos Estados Unidos o feminismo negro. Uma vez que, o feminismo até então estabelecido, não apenas na academia, mas também nos movimentos sociais, não colocava em suas pautas de lutas o recorte racial.

Desta forma, é importante ressaltar que o feminismo negro tem conseguido abarcar as especificidades da mulher negra que não foram abarcadas pelo feminismo pensado por teóricas brancas. De acordo com González (1984), as concepções deste feminismo no Brasil são necessárias, uma vez que problematizam de modo específico pela historicidade do mesmo. Neste sentido, observa-se que os feminismos brancos,

[...] padeciam de duas dificuldades para as mulheres negras: de um lado, o viés eurocentrista do feminismo brasileiro, ao omitir a centralidade da questão de raça nas hierarquias de gênero presentes na sociedade, e ao universalizar os valores de uma cultura particular (a ocidental) para o conjunto das mulheres, sem as mediações que os processos de dominação, violência e exploração que estão na base da interação entre brancos e nãobrancos, constituísse em mais um eixo articulador do mito da democracia racial e do ideal de branqueamento. Por outro lado, também revela um distanciamento da realidade vivida pela mulher negra ao negar toda uma história feita de resistências e de lutas, em que essa mulher tem sido protagonista graças à dinâmica de uma memória cultural ancestral - que nada 
tem a ver com o eurocentrismo desse tipo de feminismo (BAIRROS, 2000. p. $57)$.

Para evitar esse viés eurocentrista é importante pensar o feminismo de maneira interseccional $^{5}$, como Kimberlé Crenshaw (2002) aponta, pois o lugar no qual a mulher negra se situa determinará a interpretação sobre o duplo fenômeno do racismo e do sexismo.

Para Lélia González (1984), o racismo se constitui como a sintomática que D 1 caracteriza o simbólico cultural brasileiro, articulando-

Uma das grandes contribuições do feminismo negro tem a ver com a inclusão do quesito cor/raça nos formulários de notificação que fazem parte das fichas de

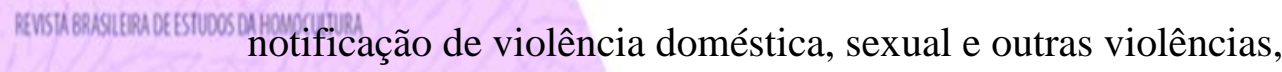

Dentre as contribuições do feminismo negro, ocupa lugar privilegiado a incorporação da temática da saúde e dos direitos reprodutivos na agenda da luta antirracista e o reconhecimento das diferenças étnicas e raciais nessa temática (...) Nessa perspectiva, a luta pela inclusão do quesito cor, sobretudo nos sistemas de classificação da população, tem se constituído um desafio permanente e objeto da ação política de aguerridas ativistas [...] (CARNEIRO, 2003, p.123).

Partindo da análise dos dados constantes no Sistema de Informação de Agravos de Notificação, as pesquisas que criaram o Mapa da Violência Contra a Mulher 2012 (WAISELFISZ, 2013) e o Mapa da Violência 2015: Homicídios de Mulheres no Brasil (WAISELFISZ, 2015) chegaram a alguns apontamentos,

a) Com poucas exceções geográficas, a população negra é vítima prioritária da violência homicida no País; b) As taxas de homicídio da população branca tendem, historicamente, a cair, enquanto aumentam as taxas de mortalidade entre a população negra; c) Por esse motivo, nos últimos anos, o índice de vitimização da população negra cresceu de forma drástica.

O gráfico a seguir demonstra esse descolamento das taxas de evolução de morte de mulheres negras e brancas, no período de 2003 a 2013, no Brasil.

\footnotetext{
5 Kimberlé Crenshaw (2002), afroamericana, professora de direito e advogada, conceitua a interseccionalidade como uma associação de sistemas múltiplos de subordinação, sendo descrita de várias formas como discriminação composta, cargas múltiplas, como dupla ou tripla discriminação, que concentra problemas e busca capturar as consequências estruturais de dinâmicas da interação entre dois ou mais eixos da subordinação.
} 
Gráfico 1 - Evolução das taxas de homicídios de mulheres brancas e negras (por 100 mil). Brasil. $2003 / 2013$

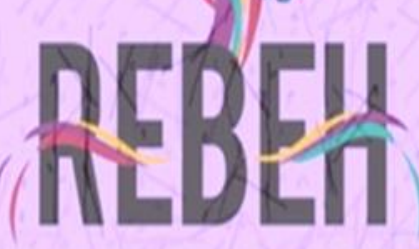

RESTABRASLER DEESTUDOS DAHOMOCUTURA



Fonte: WAISELFISZ (2015, p. 36).

O gráfico acima aponta que, levando-se em consideração que a Lei Maria da Penha é de 2006 e começou a ser aplicada em 2007, há uma probabilidade de que a criação da Lei Maria da Penha no Brasil tenha favorecido a diminuição do feminicídio das mulheres brancas. No entanto, a lei impactou pouco a vida das mulheres negras, pois observa-se um aumento crescente da taxa de feminicídio de 2007 a 2012. E, após 2012, uma pequena queda em 2013.

Segundo o Mapa da Violência 2015 - Homicídios de mulheres no Brasil, o número de homicídios de mulheres brancas caiu de 1.747 vítimas em 2003, para 1.576, em 2013. Isso representa uma queda de 9,8\% no total de homicídios do período. Já os homicídios de mulheres negras aumentaram 54,2\% no mesmo período, passando de 1.864 para 2.875 vítimas (WAISELFISZ, 2015). Em menor escala, processo idêntico se observa a partir da vigência da Lei Maria da Penha: o número de vítimas cai 2,1\% entre as mulheres brancas e aumenta $35 \%$ entre as negras (WAISELFISZ, 2015). Novamente, aqui, aparece uma tendência de diminuição de vítimas entre mulheres brancas e aumento das vítimas entre mulheres negras.

Portanto, a partir da pesquisa acima, é necessário questionar por que a Lei Maria da Penha parece ser mais efetiva para a diminuição de violência contra as mulheres brancas, pois a análise desses números demonstra que a distância relativa, entre as taxas de vítimas brancas e negras é o que o documento apresenta como: "índice de vitimização negra", que é a diferença percentual entre as taxas de homicídio de mulheres de ambos os grupos. 
Observa-se que o índice de vitimização negra, em 2003, era de 22,9\%, isto é, proporcionalmente, morriam assassinadas $22,9 \%$ mais negras do que brancas. $\mathrm{O}$ índice foi crescendo lentamente, ao longo dos anos, para, em 2013, chegar a 66,7\%. Esse diferencial nas taxas de homicídio, pela cor das vítimas, faz com que os índices de vitimização de mulheres negras apresentem de 2003 a 2012, uma escalada íngreme, sendo 2013 o único ano em que o índice cai: de 77,1\% para 66,7\% (WAISELFISZ, 2015).

Estes dados demonstram que, embora o Estado brasileiro tenha mecanismos D. legais para a diminuição da vitimização de mulheres, o racismo atua como uma - 1 -ategoria estruturante no aumento de mortes de mulheres negras, enquanto há uma diminuição de morte de mulheres brancas.

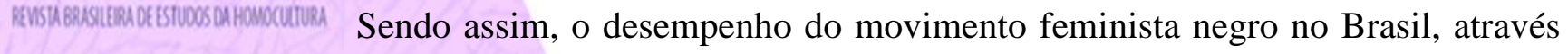
da participação das mulheres em organizações e movimentos sociais, que levassem em consideração as categorias de gênero, raça e classe de maneira interseccional, foi importante para compreender a atuação do racismo, sexismo e pobreza como agentes da violência contra as mulheres negras.

\section{Mulheres em marcha}

O dia 18 de novembro de 2015 foi um momento histórico, o dia em que as mulheres negras, vindas de vários estados do Brasil, marcharam em Brasília com o lema: "contra o racismo, e a violência, e pelo bem viver".

As pautas sobre saúde, educação e espaço de representação política acompanham há muito a luta pela sobrevivência das mulheres negras. Embora haja avanços que foram construídos e implementados como, por exemplo, as estratégias de políticas de promoção da igualdade e de enfrentamento ao racismo, pesquisas no campo das ações afirmativas e em outras áreas do conhecimento, podemos inferir que ainda são as mulheres negras que adentraram o espaço das universidades trazendo a interseccionalidade para as políticas de igualdade racial e de mulheres (GOES, 2015).

O que ocorre é que, para além de serem construídas políticas afirmativas, de reparação, de equidade para as mulheres, população negra e mulheres negras, o Estado segue um modelo estruturado pelo racismo e sexismo institucional que atua como barreiras na garantia dos direitos dos diversos segmentos da sociedade brasileira (GOES, 2015). 
Sendo assim, nada mais legítimo do que marchar contra o modelo hegemônico de sociedade que exclui parcela significativa da população para a permanência de privilégios e, que para garantia desses privilégios, aniquilam a população negra nas oportunidades e na participação efetiva do exercício da cidadania plena, e como mulheres e homens sujeitos de direitos deste País (GOES, 2015).

Em 2018 está sendo preparado o Encontro Nacional de Mulheres Negras - 30 anos que acontecerá em nos dias 06, 07, 08 e 09 de dezembro. Duas reuniões preparatórias já aconteceram e participaram 53 mulheres de onze Unidades da D. Federação (Acre, Bahia, Distrito Federal, Espírito Santo, Goiás, Minas Gerais, Tito Pernambuco, Rio Grande do Sul, Rio de Janeiro, São Paulo, Tocantins).

\section{kustu enckequ defstuos Considerações Finais}

Ao passo que nos lançamos a compreender a categoria gênero, vimos como articulá-la como flexão analítica da sociedade. No mesmo passo, identificamos os limites da compreensão sobre quais mulheres podemos assumir como base para análise sócio histórica. Isto nos leva a questões sobre as marcas identitárias e como as mesmas influenciaram os debates sobre o feminismo negro e sua proposta interseccional.

Foi o conceito de interseccionalidade e sua articulação com gênero que fez com que o feminismo negro pudesse expor esta opressão em mais de uma frente: o racismo e o sexismo. Nosso debate com os movimentos sociais, expressos aqui pela Marcha das Mulheres Negras, foi necessário pois é o fato social e histórico, a marcha em si, que intersecciona o combate a esta dupla opressão.

Concluímos que se inaugurou, a partir do uso do gênero como categoria de análise, a possibilidade de pensarmos nas diferenças apresentadas pelas respostas - e propostas feministas. $\mathrm{O}$ movimento de mulheres negras organizado ao sair à rua, exigir o fim do racismo, da violência e marchar pelo bem viver das mulheres negras nos mostrou a importância de nos atentarmos aos dados alarmantes da violência e, sobretudo, como de modo civil podemos enfrentá-la.

\section{Referências}

BAIRROS, Luiza. Lembrando Lélia Gonzalez. In: WERNECK, Jurema; MENDONÇA, Maisa e WHITE, Evelyn C. O livro da saúde das mulheres negras nossos passos vêm de longe. Rio de Janeiro, Criola/Pallas, 2000. 
CARNEIRO, Sueli. Me ensinaram a ser mais branca do que negra... Jornal Mulherio, ano IV, n. 18. 1984

Mulheres em Movimento. In: Estudos Avançados v. 17 n. 49, 2003. Disponível em: <http://www.scielo.br/scielo.php?script=sci_arttext\&pid=S0103$40142003000300008>$. Acesso em 14 Abr. 2016.

Enegrecer o feminismo a situação da mulher na américa latina. 2011 Disponível em: <http://arquivo.geledes.org.br/em-debate/sueli-carneiro/17473-suelicarneiro-enegrecer-o-feminismo-a-situacao-da-mulher-negra-na-america-latina-a-partirde-uma-perspectiva-de-genero>. Acesso em: 15 Abr. 2016.

BERNARDINO-COSTA, Joaze. Decolonialidade e interseccionalidade emancipadora: a organização política das trabalhadoras domésticas no Brasil. Soc. estado, Brasília, v. 30, n. 1, p. 147-163, Apr. 2015. Disponível em: Shttp://www.scielo.br/scielo.php?script=sci_arttext\&pid=S0102-

69922015000100147\&lng=en\&nrm=iso>. Acesso em 21 ago. 2017. http://dx.doi.org/10.1590/S0102-69922015000100009.

CRENSHAW, Kimberlé. Documento para o encontro de especialistas em aspectos da discriminação racial relativos ao gênero. Revista Estudos Feministas, v.10, n.1, p.171188. 2002.

FRASER, Nancy. A luta pelas necessidades: Esboço de uma teoria crítica socialistafeminista da cultura política do capitalismo tardio. Debate Feminista. Cidadania e Feminismo. São Paulo/México: Edição Especial em Português, 2000.

FRIEDAN, Betty. Mística Feminina, Editora Vozes Limitada, Petrópolis, Rio de Janeiro, 1971.

GOES, Emanuelle. Mulheres Negras em Marcha, esses passos vêm de longe. Disponível em: <http://www.geledes.org.br/mulheres-negras-em-marcha-esses-passosvem-de-longe/>. Acesso em 04 de abr de 2016.

GONZALEZ, Lélia. Racismo e sexismo na cultura brasileira, In: Revista Ciências Sociais Hoje, Anpocs, 1984, p. 223-244.

GONZALEZ, Lélia (1988). A categoria político-cultural de amefricanidade. Tempo Brasileiro, n. 92/93: 69-82.

MACHADO, Helena Vitória dos Santos. O processo de adesão aos 36 anos do Movimento Negro Unificado. jun 2014. Disponível em: $<\mathrm{http}$ ://www.geledes.org.br/processo-de-adesao-os-36-anos-de-movimento-negrounificado-mnu/\#ixzz43LmAAzv7>. Acesso em: 19 mar. 2016.

MOREIRA, Núbia. O feminismo negro brasileiro: um estudo do movimento de mulheres negras no Rio de Janeiro e São Paulo. Dissertação de Mestrado. Universidade de Campinas, Instituto de Filosofia e Ciências Humanas. Campinas, São Paulo, 2007.

RUFFATO, Luiz. Mas há racismo no Brasil? Texto eletrônico. Disponível em: <https://www.geledes.org.br/mas-ha-racismo-no-brasil/> 24/11/2016. Acesso em: 05 mai. 2018

SANTOS, Milton. Cidadania mutilada. In: O preconceito. Julio Lerner editor. São Paulo; Imprensa Oficial do Estado, 1996/1997. 
SCOTT, Joan. Gênero: uma categoria útil de análise histórica. Educação \& Realidade. Porto Alegre, vol. 20, $\mathrm{n}^{\mathbf{o}}$ 2, jul/dez, pp. 71-99,1995.

WAISELFISZ, J. J. Mapa da Violência 2012. Os novos padrões da violência homicida no Brasil. São Paulo, Instituto Sangari, 2011.

Mapa da Violência 2015: Homicídio de mulheres no Brasil. Brasília, Faculdade Latino-Americana de Ciências Sociais - Flacso, 2015.

\section{GENDER AND RACE:}

\section{INTERSECTIONS, SOCIAL MOVEMENTS AND COPING WITH} VIOLENCE

Abstract: The objective of this article is to establish a relation between the concept of gender as a category of analysis with the theoretical corpus of what we delimit as black feminism. To do so, it is necessary to expose the limits and possibilities of the genre as a category according to Joan Scott, as well as to present authors who have observed the needs of feminism intersected with the debate on issues of race. It is at the heart of this debate that we verify the actions of coping with violence promoted by organized social movements, namely, and especially the Black Women's March. The flow of our analysis is guided by three distinct moments: genealogical understanding of gender as a category of analysis; the debates about identity and negritude from feminist readings and the critical account of the formation movement of the Black Women's March.

Keywords: Gender; Race; March of the black women.

Recebido em: 05/08/2018

Aprovado em: 11/10/2018 